\title{
Spatial assessment of animal manure spreading and groundwater nitrate pollution
}

\author{
Roberta Infascelli ${ }^{1}$, Raffaele Pelorosso ${ }^{2}$, Lorenzo Boccia ${ }^{1}$ \\ ${ }^{1}$ Department of Agricultural Engineering and Territory, University of Naples Federico II, Portici, Naples, \\ Italy; ${ }^{2}$ Department of Environment and Forestry (DAF), Engineering Group, Tuscia University, Viterbo, \\ Italy
}

\begin{abstract}
Nitrate concentration in groundwater has frequently been linked to non-point pollution. At the same time the existence of intensive agriculture and extremely intensive livestock activity increases the potential for nitrate pollution in shallow groundwater. Nitrate used in agriculture could cause adverse effects on human and animal health. In order to evaluate the groundwater nitrate pollution, and how it might evolve in time, it is essential to develop control systems and to improve policies and incentives aimed at controlling the amount of nitrate entering downstream water systems. The province of Caserta in southern Italy is characterized by high levels of animal manure loading. A comparison between manure nitrogen production and nitrate concentration in groundwater was carried out in this area, using geostatistical tools and spatial statistics. The results show a discrepancy between modelling of nitrate leaching and monitoring of the groundwater and, moreover, no spatial correlation between nitrogen production in livestock farms and nitrate concentration in groundwater, suggesting that producers are not following the regulatory procedures for the agronomic use of manure. The methodology developed in this paper could be applied also in other regions in which European Union fertilization plans are not adequately followed.
\end{abstract}

Keywords: non-point pollution, manure, nitrate, spatial analysis, human health.

\section{Introduction}

During the last few decades a significant decrease in water quality has been observed in different parts of the world, despite considerable efforts towards cleaning up point pollution sources. The decrease in water quality has been attributed to an increased contribution of non-point pollution sources (NPS), which are, in turn, strongly dependent on land use. The literature reports many cases referring to this issue (Haycock and Muscutt, 1995; Sims et al., 1999; Arheimer et al., 2004; Viaud et al., 2004).

\footnotetext{
Corresponding author:

Lorenzo Boccia

Department of Agricultural Engineering and Territory

University of Naples Federico II

Via Università 100, 80055 Portici, Naples, Italy

Tel. +39081 2539151; Fax +390812539156

E-mail: lorenzo.boccia@unina.it
}

There is general agreement on considering agriculture the main NPS of nutrients to water (Sharpley et al., 1994; Frost, 1999; Rekolainen et al., 1999; Sims et al., 1999).

Groundwater characterized by high concentration of nitrate is unsuitable for human consumption (Thayalakumaran et al., 2008). Nitrate itself is a compound of low toxicity, but nitrate can be reduced to nitrite, the most toxic form with regard to human health, which can cause infantile methemoglobinemia. In addition, carcinogenic Nnitrosamines can be formed from nitrite (Fine et al., 1977), which is suspected of causing gastric cancer and other malignancies.

Elevated nitrate level in water can also modify the stability and diversity of aquatic ecosystems (Tesoriero et al., 2000). Knowledge and understanding of the processes and conditions that can influence nitrate concentration in water form the 
base with respect to improving policies and targets aimed at controlling nitrate pollution.

In European and national regulations (e.g. EEC 91/676; Italian Legislative Decrees 152/99 and $258 / 00$ ), nitrate leakage is considered a pollution indicator which is related, amongst other factors, to livestock rearing activities (Garnier et al., 1999). The European Union (EU) regulation Directive 96/61 EC, Integrated Pollution Prevention and Control (IPPC), requires that an integrated approach to pollution deriving from livestock activities should be implemented. This takes into consideration the possible impacts on the three environmental compartments water, air and soil and aims to decrease pollutants at the origin of the production chain.

The Italian Ministry for Agricultural and Forestry Policies has ruled, by means of the Ministerial Decree issued on 7 April 2006, that the regions are required to practice an integrated management of effluents by promoting ways of livestock farming and feed selection aimed at reducing nitrogen content in manure. Some authors (Burton and Turner, 2003; Westerman and Bicudo, 2005) maintain that, in this context, the goal should be to make the "waste" a resource that can be utilized and not just discarded. The large quantities of slurry and manure that are produced every year in areas in which animals are raised, could be an important source of organic matter and nutrients. Recycling this waste via land application could also lead to soil improvement with regard to porosity, structure and waterholding capacity (Ramos et al., 2006). In order to decide the right balance between reuse and disposal, "best management practices" need to be identified. Moreover, manure management has to involve the identification and evaluation of the criteria necessary for the design and the selection of optimal management systems (Kamarkar et al., 2007; McColl and Aggett, 2007).

Although manure is a valuable source of plant nutrients, it can also be a source of pollution and a threat to the environment unless managed carefully. Studies have revealed that farm management is more effective than farm structure in reducing nutrient surplus (Ondersteijn et al., 2003). Improving management also has the potential to improve economics (Kuipers and Mandersloot, 1999; Osei et al., 2003). Despite the obvious benefits of optimising nutrient management, practices deemed the best may be unsuitable in some contexts due to social constraints. Therefore, environmental interventions must be flexible and adaptable in the area, where the local traditional farm management practices often have deep roots which may contribute to a strong initial resistance to change.

Income from the sale of milk from dairy cattle and buffalo plays a major role in the regional economy of the Campania region of southern Italy, which is characterized by an undeveloped social fabric. Indeed, the milk income has been estimated at about 600 million €/year to which should be added incomes from the cheese industry. The value of buffalo milk is $1.1 € / 1$ with a production of about $1,9001 /$ lactation, while the value of cattle milk is $0.4 € / 1$ with a production of 5,000 1/lactation. Hence the income created from dairy production is essential for regional economic improvement.

At present, dairy production from cattle is taxed by the government. This policy of milk quotas has significantly boosted the breeding of buffalo, whose milk is not subject to the tax. This expansion overlaps pre-existing intensive agriculture in a context of high fragmentation of agricultural holdings and a low adherence to environmental management methods.

This paper suggests an analytical method for evaluating whether the regulations are being respected, and for evaluating the efficacy of actions undertaken to reduce nitrate concentration in shallow groundwater. Geostatistical tools were used to carry out a spatial analysis of the environmental and the natural variables involved in this issue. The idea was to identify a methodology for the comparison between the nitrate pollution found within the territory and the potential output of pollutant. The lack of correspondence can play the role as a guideline for the next studies aimed at the identification of the real fate of manure. 


\section{Materials and methods}

\section{Study site}

The province of Caserta, which is part of the Campania region in southern Italy (Fig. 1), was chosen as study area. According to the $5^{\text {th }}$ Italian Agriculture Census in 2000 (Italian National Institute of Statistics - ISTAT), the middle and lower valleys of the Volturno-Garigliano river system with its 3,273 registered livestock farms belong to the most productive livestock rearing areas in Italy. Focusing on the most economically significant animal species reared in Campania, the 2000 Agricultural Census showed a population of 94,278 river buffaloes (Bubalus bubalis) and 52,647 dairy cattle on a total agronomic surface (SAT) of 107,400 ha, representing the entire Caserta district. These values are interesting when compared with the regional buffalo population of 130,732 head, and dairy cattle population of 212,267 head. The

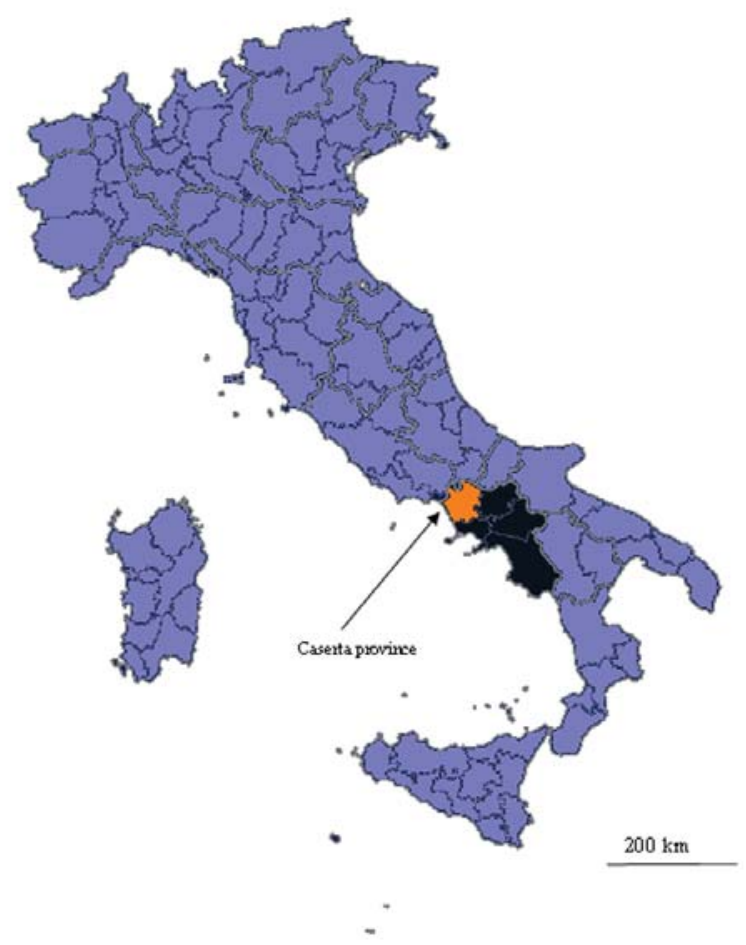

Fig. 1. Location of the Caserta province in southern Italy. number of dairy cattle and river buffaloes reared in the study area was assessed, as were the importance of livestock rearing for the local economy and its environmental impact related to nitrate leaching.

The study area's hydrogeology is characterized by a series of independent, suspended, unconfined aquifers, with poor water circulation; while the deep groundwater has a distinctive flow from east to west (Allocca et al., 2003) (Fig. 2). The soils of the province of Caserta are characterized by clay-loams, whose representative texture is sand $(35 \%)$, silt $(35 \%)$ and clay $(30 \%)$. Their average $\mathrm{pH}$ is 7.7 , while they contain $1.5 \%$ organic matter which is related to soil nitrogen forms. Studies have shown the percentage of total nitrogen to be approximately $0.1 \%$.

\section{Nitrogen fertilization}

The balance of the average soil nitrogen content includes also the quantities that are required to fer-

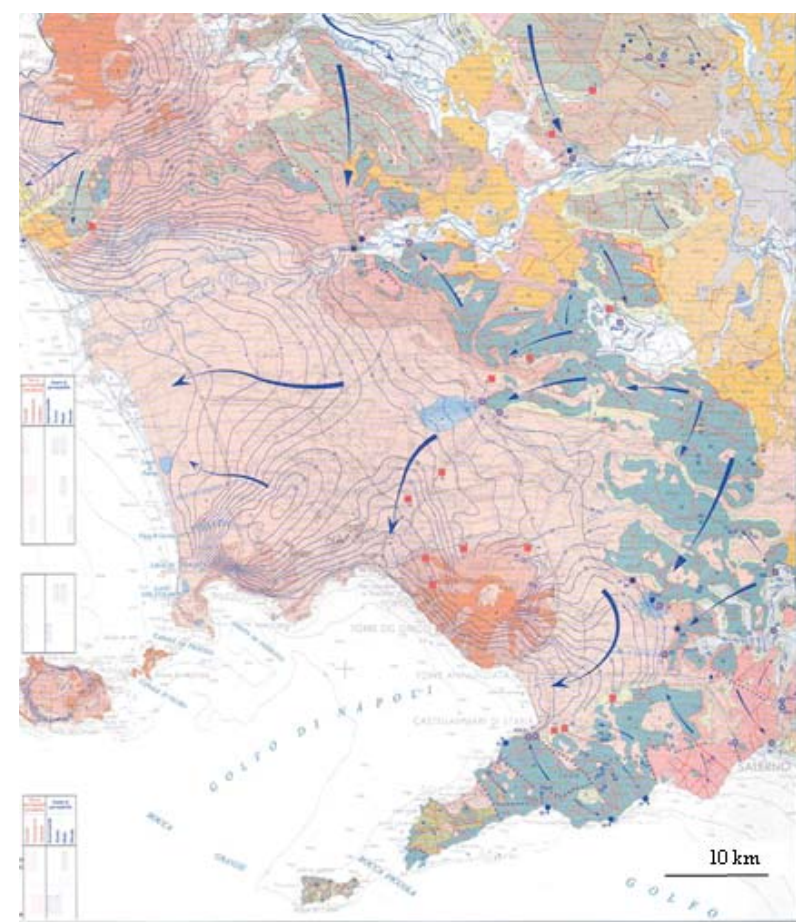

Fig. 2. Hydrogeological map of the Campania region extracted from the "hydrogeological map of souther Italy". 
tilize the crops typical of the study zone. The Campania regional government has developed a "Fertilization Guide" (Ingenito et al., 2003) to estimate nitrogen needs according to soil features and crop type which can be calculated by the following formula:

$$
\mathrm{NF}=\mathrm{W}-\mathrm{X}+\mathrm{Y}+\mathrm{Z}
$$

where "NF" is nitrogen fertilization, "W" crop needs, "X" benefits of soil fertility, "Y" leakage, and "Z" immobilization and loss. Crop needs are calculated by multiplying removals and yields (see Table 1) and are related to each specific crop. The benefits of soil fertility are estimated based on the carbon/nitrogen $(\mathrm{C} / \mathrm{N})$ ratio for the typical soil. Specifically it is possible to identify two kinds of benefits:

(i) those from organic matter mineralisation (X1) are $35 \mathrm{~kg} \mathrm{~N} / \mathrm{ha}$ and are calculated based on a the $\mathrm{C} / \mathrm{N}$ ratio between 9 and 12 and an organic matter content equal to $1.5 \%$; and

(ii) those from the initial nitrogen content that can assimilated (X2), i.e. about $1 \%$ of total nitrogen, are $25 \mathrm{~kg} \mathrm{~N} / \mathrm{ha}$, considering $\mathrm{N}_{\text {tot }}=1 \%$.

Hence, benefits due to soil fertility are $\mathrm{X} 1+\mathrm{X} 2=$ $35+25=60 \mathrm{~kg} \mathrm{~N} / \mathrm{ha}$.

Nitrogen leakage ( $\mathrm{Y}$ ) is determined by the information in Table 2. The soils typical of the case study area are clay-loam and have moderate drainage, so nitrogen leakage is calculated as $25 \mathrm{~kg} \mathrm{~N} / \mathrm{ha}$, according to these regional rules.

Nitrogen quantities immobilized by biomass by absorption, volatilisation and denitrification are estimated by the equation:

$$
Z=(X 1+X 2) * f c
$$

where " $\mathrm{fc}$ " is a correction factor (in this case fixed as 0.275 , making $Z=16.5 \mathrm{~kg} \mathrm{~N} / \mathrm{ha}$.

By means of the above-mentioned formula for nitrogen fertilization, nitrogen needs for each selected crop are obtained as follows: alfalfa $(40 \mathrm{~kg}$ $\mathrm{N} / \mathrm{ha}$ ), corn silage (140 kg N/ha), rye grass (125 kg $\mathrm{N} / \mathrm{ha}$ ), maize (190 kg N/ha) and oats (45 kg N/ha).

\section{Site surveys}

To evaluate the impact of livestock activities on the environment, 150 wells were sampled during 1999-2000 in the Volturno-Garigliano basin and nitrate concentrations were measured using a portable reflectometer (Boccia et al., 2003). The locations of the wells were surveyed by a Garmin global positioning system (GPS). In order to evaluate the results of the European and Campania regional government policies (Regional Committee Resolution (DGR) 610, 700, 2382 - 2003) the nitrate concentrations tests were repeated for 40 wells in the period 2004-2005.

The study area was analysed by a geographical information system (GIS), using the Arcview 3.2 software (ESRI, Redlands, CA, USA). GIS has become an increasingly widely used tool to manage, analyse and visualize different datasets related to topography, land use, soil and land cover (Badri et al., 2002; Miller et al., 2004). Thanks to these tools, 2,441 livestock rearing farms were identified by analysing a series of Campania orthophotos taken in 1998 (Fig. 3). The difference between the farms registered (ISTAT, 2000) and the farms analysed

Table 1. Removals and yields of the selected study zone's crops according to regional rules.

\begin{tabular}{lcc}
\hline Crop & Removals $\left(\mathrm{kg} / 10^{-1} \mathrm{t}\right)$ & Yields $\left(10^{-1} \mathrm{t} / \mathrm{ha}\right)$ \\
\hline Alfalfa & 0.30 & 200 \\
Corn silage & 0.20 & 800 \\
Rye grass & 1.60 & 90 \\
Maize & 2.10 & 100 \\
Oats & 1.60 & 40 \\
\hline
\end{tabular}

Table 2. Amount of nitrogen leakage ( $\mathrm{kg} \mathrm{N} / \mathrm{ha})$.

\begin{tabular}{lccc}
\hline & \multicolumn{3}{c}{ Soil texture } \\
\cline { 2 - 4 } Drainage & Sandy & Loam & Clayey \\
\hline Slow & 50 & 40 & 50 \\
Moderate & 40 & 30 & 20 \\
Good & 50 & 40 & 30 \\
\hline
\end{tabular}




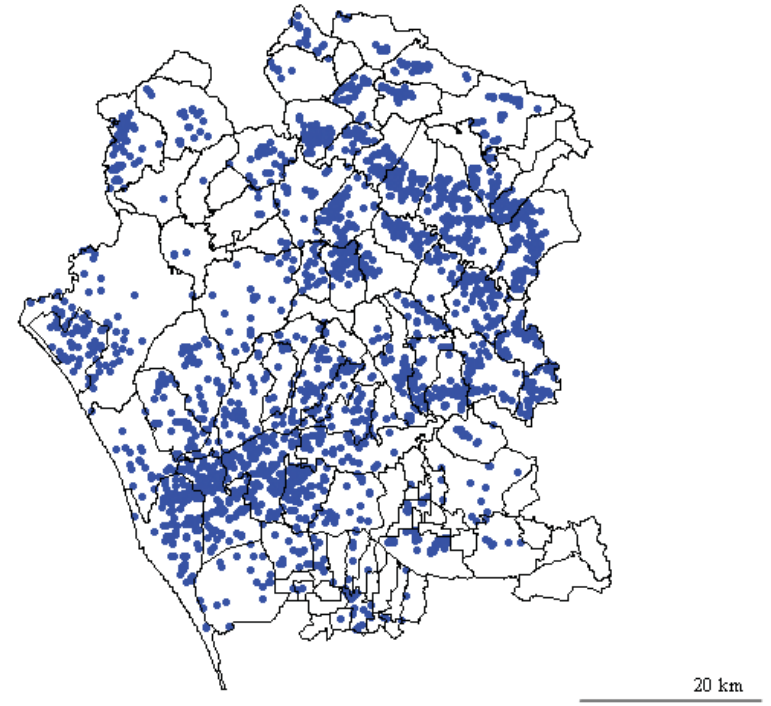

Fig. 3. Municipal limits and locations of livestock farms in the Caserta province of southern Italy.

using the orthophotos is probably due to the possible non-correspondence between the farms' registered offices (in Italy the place where an activity is registered does not necessarily coincide with the place where that activity actually takes place) and their geographical location. Based on the quantity of farms identified on orthophotos, municipal ISTAT datasets of buffalo and cattle numbers were allocated as average municipal values to each farm.

Quantities of manure and related nitrate content were calculated following the procedures established by the Italian Ministerial Decree of 7 April 2006, with reference to the Legislative Decree $152 / 1999$. The data obtained were added to the GIS dataset as a specific data layer. Hence, a comprehensive assessment of buffalo and cattle spatial locations in the province of Caserta and, consequently, of the related manure and nitrate quantities produced for each farm location, was obtained.

\section{Spatial analysis of nitrogen production}

The spatial distribution of nitrogen quantity within the territory, produced by each farm in a year, was evaluated by a convolution of the farm's spatial distribution with a weighted function characterizing the decrease in significance of the pollutant (nitrogen) presence (in $\mathrm{kg} / \mathrm{ha}$ ) as a function of the increase in distance from the farm. Because we have no information on the way farmers are using manure, we assume that the deposit of manure on field decrease as a function of the distance from the farm location. The weighted function has the following formula in polar coordinates $(r, \vartheta)$ :

$$
\rho(r, \vartheta)=\frac{3}{\pi R^{2}}\left[1-\left(\frac{r}{R}\right)^{2}\right]^{2}
$$

This function approximates the Gaussian distribution below, as follows:

$$
\rho(r, \vartheta)=\frac{1}{\pi \sigma^{2}} e^{\frac{-r^{2}}{2 \sigma^{2}}}
$$

when $=3 \sigma$. In formulas (3) and (4) “ $R$ ” represents the search radius and " $\sigma$ " the variance of the Gaussian distribution. Hence, through function (3), we assume that the pollutant loses significance for areas outside the search circle (Ter Haar Romeny, 2003).

For the case study a search radius equal to $6 \mathrm{~km}$ was chosen because the cost of spreading manure is less than or equal to the doubling of the cost of synthetic nitrogen $(0.5 € / \mathrm{kg})$ within this search radius. These assumptions were made hypothesizing a nitrogen spreading cost of $1.5 € / \mathrm{t}$ considering a distance of $6 \mathrm{~km}$ (Provolo, 2000).

\section{Spatial analysis of groundwater nitrate concentration}

Due to the intrinsic variability, number and variety of environmental and natural phenomena, the use of classical statistics to study these subjects could prove time-consuming and limiting. Therefore geostatistic tools were chosen to deal with the intrinsic environmental uncertainty. Geostatistical analysis (Goovaerts, 1997) attempts to verify whether or not the variability of a given set of data depends on the location of the measurement point. Moreover it allows a weighted interpolation of the available data, assuming that the weights are functions of the distance between data. 
Samples of nitrate concentration in wells were analysed by means of a semivariogram to model the degree of spatial dependence displaying data semivariance $\gamma(b)$ related to data distance:

$$
\gamma(b)=\frac{1}{2 N(b)} \sum_{i=1}^{N(b)}\left[\mathrm{Z}\left(x_{i}\right)-\mathrm{Z}\left(x_{i}+b\right)\right]^{2}
$$

where " $Z\left(x_{i}\right)$ " is a value at a particular location, " $b$ " the measurement distance (the so called "lag distance") and "N(b)" the number of data pairs at distance " $b$ ".

The semivariogram provides information about the continuity and the spatial variability of the process studied. An experimental semivariogram has to be fitted by a semivariogram model. For the case study, an exponential semivariogram model was selected, whose formula is:

$$
\gamma(b)=C_{0}+C\left(1-e^{\frac{-b}{a}}\right)
$$

where " $C_{0}$ " is the nugget effect and " $\left(C_{0}+C\right)$ " represents the sill and $a$ is the range.

The next elaboration was a prediction of nitrate concentration at those points that were not sampled, by means of kriging interpolation. The existence of a model of spatial dependence allows attribute values to be estimated for unsampled locations (Goovaerts, 1997). Ordinary kriging was used in this study. It entails the hypothesis that the mean may vary in the local neighbourhood within the study area. This assumption is coherent with the features of the study area. The ordinary kriging estimator is described by the equation:

$$
z^{\prime \prime}\left(x_{0}\right)=\sum_{i=1}^{N} \lambda_{i} z_{i}\left(x_{i}\right)
$$

where " $\lambda_{i}$ " are the weights, " $z\left(x_{i}\right)$ " the $N$ available data and " $z\left(x_{0}\right)$ " the unsampled location where " $z *\left(x_{0}\right)$ " is estimated. For the study case, GIS software was used to perform this type of interpolation, which was then presented in the form of a map where the attribute spatial distribution over the study area is identified by a graduated colour scale (Fig. 5). The next step was to compare the predic- tions of nitrate pollution in shallow groundwater (Fig. 5) with the spatial distribution of the annual nitrogen density produced by each farm (Fig. 4). In order to do this, a comparison method was created using GIS software. A grid of located points, with a mesh of 1,000 m, was built and the kriging prediction and nitrogen production density values were

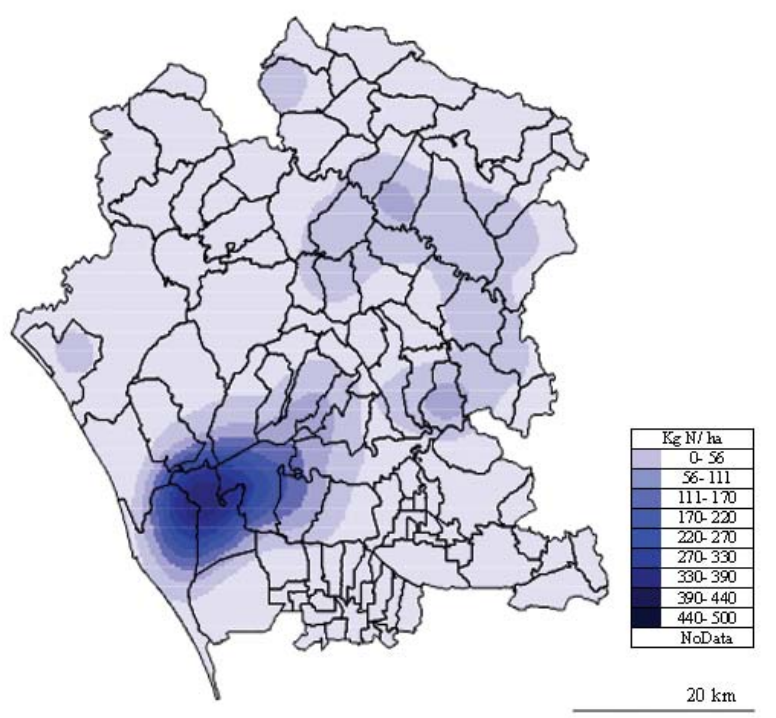

Fig. 4. Spatial distribution of nitrogen production $(\mathrm{kg} / \mathrm{ha})$ by farms in Caserta province, southern Italy.

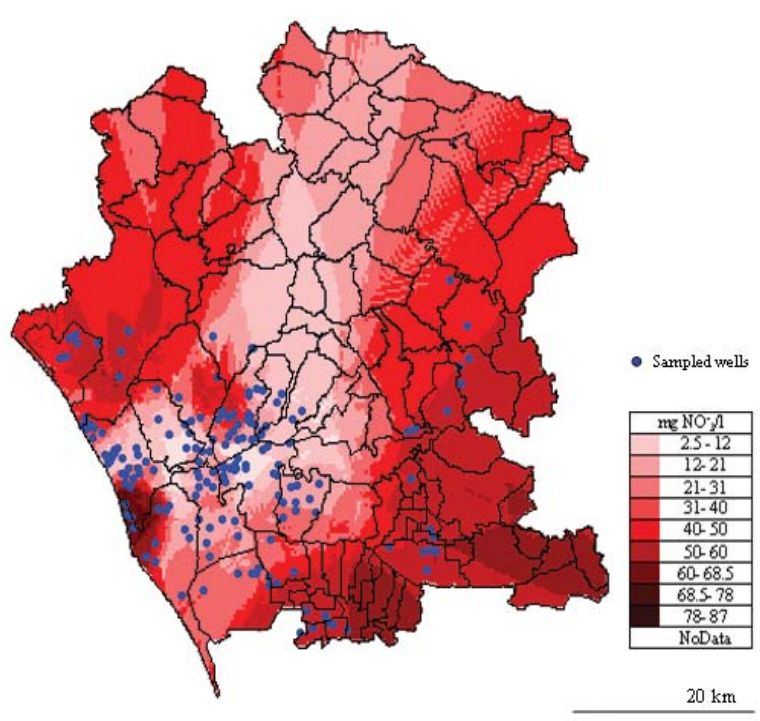

Fig. 5. Kriging prediction of nitrate concentration $(\mathrm{mg} / \mathrm{l})$ in shallow groundwater in Caserta province, southern Italy. 
extracted from the grid. The size of the mesh was chosen to allow a precise analysis of the areas surrounding the farms.

To display the possible correlation between nitrate concentration in groundwater and the presence of livestock farms, a scattergram, a tool that is widely used for such elaborations, was developed. Samples were collected in superficial canals in the area of Volturno-Garigliano in September 2007 to assess whether waste was being dumped regularly in superficial streams. Nitrate concentrations were measured by means of a portable reflectometer (model Simply distributed by Bracco, Milan, Italy, coupled with Merk Spectroquant tests codes 114563 and 100614).

\section{Results}

The data obtained, according to the methods established by the Italian Ministerial Decree of 7 April 2006, show that the province of Caserta $($ SAT $=107,400 \mathrm{ha})$ has a theoretical total nitrogen production of $14,700,000 \mathrm{~kg}$ per year.

Table 3. The 18 municipalities with large excesses in nitrogen production.

\begin{tabular}{lrrr}
\hline Municipality & Total N $(\mathrm{kg} / \mathrm{y})$ & SAT $(\mathrm{ha})$ & $\mathrm{kg} \mathrm{N} / \mathrm{ha}$ \\
\hline Alife & 405,313 & 1,714 & 236.429 \\
Alvignano & 462,782 & 2,577 & 179.565 \\
Baia e Latina & 267,852 & 1,154 & 231.986 \\
Cancello e Arnone & $2,524,091$ & 3,153 & 800.480 \\
Capua & 321,786 & 1,525 & 210.975 \\
Castel di Sasso & 130,189 & 651 & 199.817 \\
Castelvolturno & $1,509,041$ & 1,948 & 774.387 \\
Ciorlano & 445,309 & 1,221 & 364.413 \\
Grazzanise & $1,108,980$ & 2,306 & 480.871 \\
Marcianise & 255,328 & 869 & 293.517 \\
Pastorano & 321,786 & 1,083 & 297.061 \\
Piana di Monte Verna & 398,546 & 1,234 & 322.779 \\
Pietramelara & 241,390 & 672 & 359.109 \\
Pignataro Maggiore & 339,562 & 1,394 & 243.478 \\
Pontelatone & 189,476 & 698 & 271.432 \\
San Tammaro & 229,674 & 617 & 371.713 \\
Santa Maria la Fossa & 589,840 & 1,007 & 585.187 \\
Sant'Angelo d'Alife & 364,206 & 1,831 & 198.855 \\
Total & $10,105,151$ & 25,663 & \\
\hline
\end{tabular}

The most interesting observation specifically concerns 18 municipalities (Table 3) where annual nitrogen production per ha exceeds the regulatory threshold of $170 \mathrm{~kg} / \mathrm{ha}$ (Dir. 96/61/EC). For example, in "Cancello e Arnone" the concentration of manure nitrogen is approximately $800 \mathrm{~kg} / \mathrm{ha}$ per year. These 18 municipalities have a total agronomic surface equal to 25,663 ha, of which $40 \%$ $(10,265 \mathrm{ha})$ is cultivated with corn silage and rye grass with the remaining fraction divided equally between alfalfa, maize, oats and other crops (15\% each).

Table 4 demonstrates that no more than 4,000 t/y of nitrogen is sufficient to fertilize crops, but the total nitrogen production from manure is about $10,000 \mathrm{t} / \mathrm{y}$ (Table 3). The data sampled in 19992005 were compared with the regulatory thresholds (Italian Legislative Decree 152/1999) for sensitive areas (nitrate concentration of $25 \mathrm{mg} / \mathrm{l}$ ) and vulnerable areas (nitrate concentration of $50 \mathrm{mg} / \mathrm{l}$ ); the comparison showed that $36 \%$ of the samples had a nitrate concentration of approximately $50 \mathrm{mg} / \mathrm{l}$, while in $22 \%$ of the samples the concentration was between 25 and $50 \mathrm{mg} / \mathrm{l}$, and only $42 \%$ of the samples showed a concentration of below $25 \mathrm{mg} / \mathrm{l}$. The water sampling data were also processed by statistical software programmes (Surfer 8 and SPSS), to evaluate their coherence and their statistical distribution. The skewness of the original experimental data was reduced by logarithmic transformation and by removing the extreme values (Fig. 6) (Goovaerts, 1997). Hence, the average dissimilarity between data was assessed by an exponential semivariogram model (Fig. 7), characterized by a best-fit nugget effect equal to 0.14 .

Ordinary kriging predictions were estimated based on the semivariogram (Fig. 7). These predictions of nitrate concentration in shallow groundwater were then compared with the spatial distribution of nitrogen density produced by each farm in a year (Fig. 4). For this aim the comparison method, based on a grid with a mesh of $1,000 \mathrm{~m}$ and discussed in the previous section, was used. Data pairs were compared through a scattergram (Fig. 8) where 
Table 4. Nitrogen fertilization rate related to the 18 municipalities recorded in Table 3.

\begin{tabular}{lcrrr}
\hline Crop & Kg N/ha & \% ha SAT & ha SAT & kg N*ha-1*ha SAT \\
\hline Alfalfa & 40 & $15 \%$ & 3,850 & 154,000 \\
Corn silage + Lolium multiflorum & $265(140+125)$ & $40 \%$ & 10,265 & $2,720,225$ \\
Maize & 190 & $15 \%$ & 3,850 & 731,500 \\
Oats & 45 & $15 \%$ & 3,850 & 173,250 \\
Other crops & 55 & $15 \%$ & 3,850 & 211,750 \\
Total & & & $3,990,725$ \\
\hline
\end{tabular}

(a)

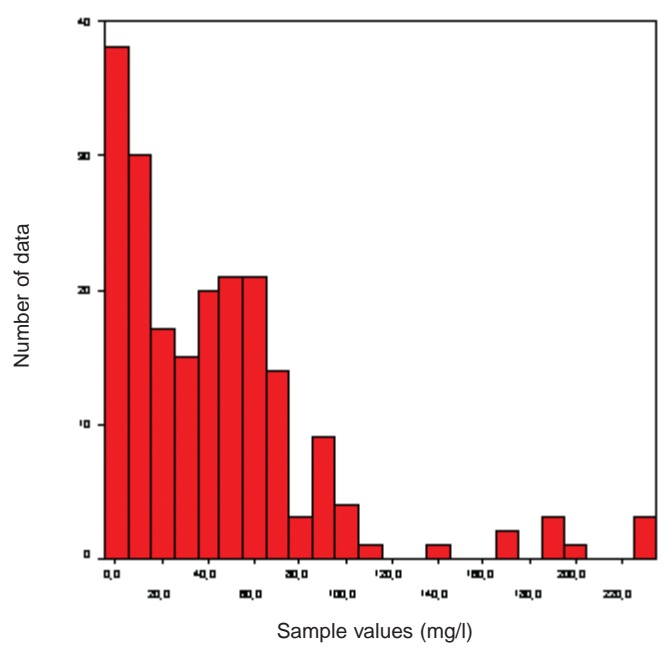

(b)

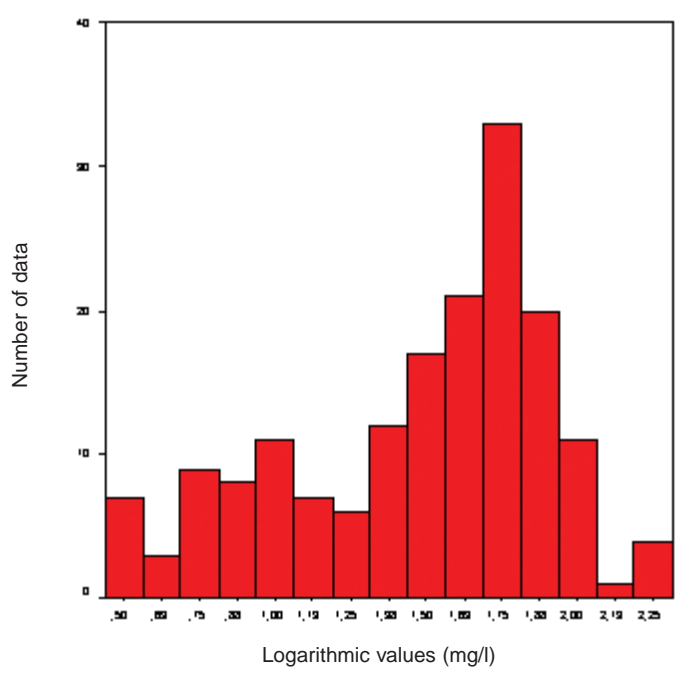

Fig. 6. (a) Original sampled data distribution. (b) Sampled data distribution after logarithmic transformation. Note: the ratio between nitrate and nitrate-nitrogen is 4.42 ).

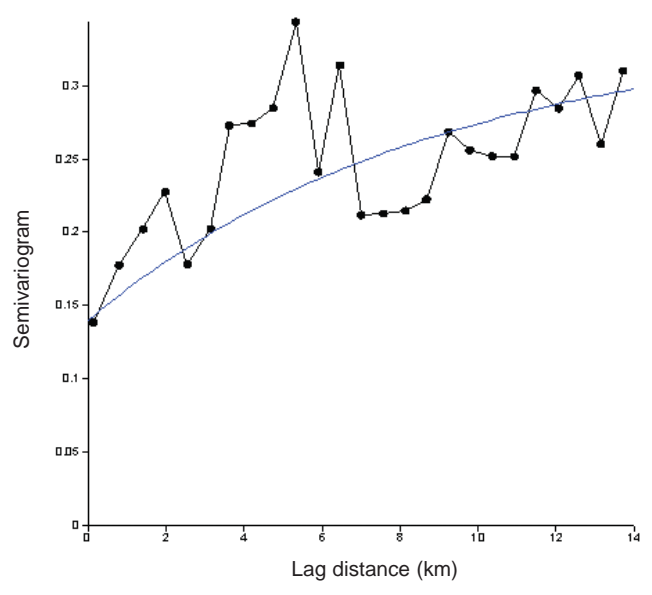

Fig. 7. Semivariogram of nitrate concentration in groundwater.

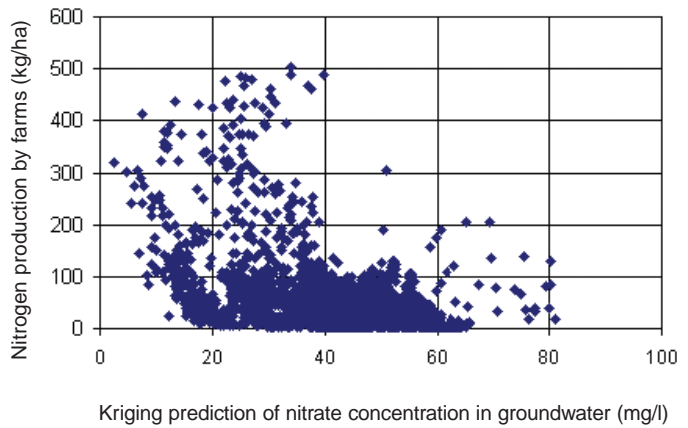

Fig. 8. Scattergram: comparison between nitrate concentration forecast in groundwater and nitrogen production. 
model-predicted nitrate concentrations in groundwater were compared with the average nitrogen production by farms. If a correlation between the animal loading and the pollution had existed, the correlation coefficient " $\rho$ " would have been greater than 0.5 and the scattergram would have shown data whose trend could be modelled by an increasing monotonic function. However, the correlation coefficient " $\rho$ " turned out to be -0.38 , which demonstrates that the correlation between animal density and nitrate pollution in the groundwater was negative rather than positive. Table 5 shows nitrate concentration in superficial streams.

Table 5. Nitrate concentration in superficial streams.

\begin{tabular}{lccc}
\hline No. & Longitude (East) & Latitude (North) & Nitrate $(\mathrm{mg} / \mathrm{l})$ \\
\hline 1 & $13^{\circ} 59^{\prime} 32^{\prime \prime}$ & $41^{\circ} 00^{\prime} 12^{\prime \prime}$ & 11.07 \\
2 & $13^{\circ} 59^{\prime} 29^{\prime \prime}$ & $41^{\circ} 00^{\prime} 10 "$ & 6.67 \\
3 & $14^{\circ} 00^{\prime} 54^{\prime \prime}$ & $41^{\circ} 00^{\prime} 51^{\prime \prime}$ & 8.53 \\
4 & $13^{\circ} 59^{\prime} 49^{\prime \prime}$ & $40^{\circ} 59^{\prime} 28^{\prime \prime}$ & 56.74 \\
$5^{*}$ & $13^{\circ} 56^{\prime} 18^{\prime \prime}$ & $41^{\circ} 02^{\prime} 04^{\prime \prime}$ & 5.22 \\
6 & $13^{\circ} 55^{\prime} 08^{\prime \prime}$ & $41^{\circ} 04^{\prime} 40^{\prime \prime}$ & 3.97 \\
7 & $13^{\circ} 53^{\prime} 34^{\prime \prime}$ & $41^{\circ} 06^{\prime} 04^{\prime \prime}$ & 16.40 \\
8 & $13^{\circ} 51^{\prime} 17^{\prime \prime}$ & $41^{\circ} 09^{\prime} 52^{\prime \prime}$ & 10.09 \\
9 & $13^{\circ} 49^{\prime} 15^{\prime \prime}$ & $41^{\circ} 14^{\prime} 38^{\prime \prime}$ & 7.76 \\
$10^{* * *}$ & $13^{\circ} 46^{\prime} 13^{\prime \prime}$ & $41^{\circ} 14^{\prime} 19^{\prime \prime}$ & 6.16 \\
\hline
\end{tabular}

*Volturno River, **Garigliano River

\section{Discussion}

This study has evaluated results obtained by putting EU and regional manure management regulations into effect. The study region followed community directives and thus fertilizer application planning was enforced, at least formally. However, there is a suspicion that, in reality, manure management has been moving in a direction opposite to that intended by the EU and that the discipline of EU nutrient management, both in the study area and in other EU zones, is being circumvented (Neeteson, 2000). The paper tried to identify the critical features of this complex system and investigated whether it would be opportune, or otherwise, to introduce manure treatment technologies, even if they are temporary or considered to be "end of the pipe" technologies and as such would not be considered ecologically correct in other contexts.

The method to identify livestock rearing farms through the analysis of orthophotos, adopted in this study, appears to be well-founded. It allowed, within a margin of error, a representation of livestock farms in the study area which is very close to the true location. The margin of error does not depend on a geographical uncertainty, but on the uncertainty of the actual number of animals in livestock rearing farms. This kind of approximation was handled by distributing the environmental impact of the farm, using a search radius of $6 \mathrm{~km}$. This distance is comparable to the distances that were used for the kriging prediction (the maximum lag distance equal to $12 \mathrm{~km}$ ).

It is interesting to compare in depth the geographical locations of the livestock rearing farm (Fig. 3) and the spatial distribution of annual nitrogen density produced by the farms (Fig. 4). Through the generation of map layers, it was possible to create from discrete data a map of the probable distribution of nitrogen production. Comparing Figures 3 and 4 , it is possible to deduce that the nitrogen production per ha is not uniformly high throughout the area even where there are many farms, because the average number of animals is low on some farms. Hence, proportional information about the possible quantity of nitrogen leaching, that would be obtainable if the manure were managed following the regulations, is given.

Tables 3 and 4 provide the total nitrogen required for crop production and the total nitrogen in manure at the municipality scale showing 18 municipalities with large nitrogen excesses. The ratio between the total nitrogen required for crop production and the total nitrogen in manure is 1 to 2 . Such a nitrogen loading is, in practise, unsustainable in the study area, where there are few or no facilities suited to storing large quantities of manure. Furthermore there are specific areas and periods in which spreading manure is allowed, in reference to regional regulations (DGR 610, 2/14/2003). In view of this, it is necessary to determine the quantity of 
manure nitrogen that can effectively be used through "good agricultural practice" which would ensure good crops, while also preserving water streams. It should be borne in mind that all the farms in the study area are not rearing livestock and that it is unlikely that farms which do not would permit regular manure spreading on their soil.

It is clear that considering the 18 critical communes, the amount of effectively manageable manure nitrogen is about 4,000-5,000 t/y, assuming that $80 \%$ of the SAT is suitable for spreading, versus a theoretical production of $10,000 \mathrm{t} / \mathrm{y}$ of manure nitrogen. The excess nitrogen, 5,000-6,000 t/y, should be handled through a more complete, well-structured system. However, such management systems are in most cases not available in the region. Consequently a great quantity of synthetic fertilizer, almost $100 \%$ of nitrogen fertilizer needs, is used in the study area (Onorati et al., 2003). It follows that nitrate pollution of shallow groundwater would be expected, and indeed has been found in our 1999-2005 monitoring study of nitrate concentration in wells.

The manipulation of the groundwater nitrate data performed to construct the semivariogram suggests that the spatial correlation of the data also depends on the sampling methods. In this view, Figure 7 shows that the geostatistical approach is essential in order to deal with the uncertainty that is typical of regionalised natural variables. Indeed, the experimental semivariogram shows peaks, probably due to sampling depths, to variation in sampling times and to the influence of different crops on the territory analysed. These sources of uncertainty were handled by kriging.

The Arcview 3.2 generated comparisons between the maps showing the spatial distribution of nitrogen produced by each farm and the predicted spatial distribution of nitrate concentration in groundwater. These comparisons were, however, unsuitable for a precise analysis, which was the reason why a comparison method, using a grid, was introduced.

It is necessary to verify the correlation between the nitrate concentration found in the sample wells and the predicted nitrogen production (Fig. 8). Since the correlation coefficient $\rho$ equals -0.38 , this suggests that no positive correlation between predicted nitrogen production and groundwater nitrate exists, rather the contrary. A possible explanation is that manure is being disposed as a waste rather than being utilized agronomically, otherwise a closer correlation would be expected between high animal density and high shallow groundwater nitrate concentration.

In this context an evaluation of the economic aspects of manure management takes on great importance. It should be considered that the cost for spreading manure (about $1.5 € / \mathrm{t}$ at a distance of 6 $\mathrm{km})$ may limit compliance with land management plans. Moreover spreading activities entail considerable vehicle movements and labour, given the low nitrogen concentration in manure $(3 \%$ ), approximately 100 days annually available for land application and tanks with a maximum capacity of $10 \mathrm{~m}^{3}$.

The absence of agronomic use of manure is demonstrated by the data collected during the surface water sampling campaign in the Volturno and Garigliano river valleys (Table 5 and Fig. 8). Only a single value exceeded the legal threshold for nitrate concentration in surface water $(50 \mathrm{mg} / \mathrm{l})$. However, this is not surprising if the river flow rates are taken into consideration. For example, rivers such as the Volturno and Garigliano are characterised by average flows of $80 \mathrm{~m}^{3} / \mathrm{s}$ and $120 \mathrm{~m}^{3} / \mathrm{s}$, respectively, values allowing the dilution of great quantities of nutrients. The Volturno river alone, with its average flow of $80 \mathrm{~m} 3 / \mathrm{s}$, can transport about $13500 \mathrm{t} / \mathrm{y}$ of nitrate into the sea, a large amount compared to the manure nitrogen production in the province of Caserta.

The continuing growth of the livestock industry in both developed and developing countries coupled with the implementation of rigorous environmental regulations and protocols underline the importance of appropriate manure management systems and practices. Manure management has to be handled by a systematic approach once the criteria for optimal management have been determined.

This study has shown that the shallow groundwater in the study area is polluted. Nevertheless, the concentrations of the pollutant are not proportional 
to the local livestock densities. Significant nitrate concentrations approaching EU levels of concern have been found in streams, rivers and canals, which suggests that manure is being disposed of, in or near surface water bodies. The absence of a correlation between the nitrogen produced by the farms annually and the nitrate concentration in shallow groundwater in the same area supports this hypothesis. Moreover, studies performed on the subject show that large reductions in nutrient inputs do not necessarily cause an immediate response in terms of water quality improvement, particularly in mediumsized and large areas (Stålnacke et al., 2003). It has also been shown (Frost, 1999) that rather than the present emphasis on soil nutrient content and soil erosion, priority should be given to studying the receiving waters.

It is necessary to set this framework as part of the economic context for manure management. Indeed, livestock farmers today are still reluctant to adopt manure best-management procedures, first of all for economic reasons, i.e. using synthetic fertilizers is easier, faster, more practical, and therefore cheaper, than using manure nutrients even if the cost of buying synthetic fertilizer is $0.5 € / \mathrm{kg}$, versus $1.5 € / \mathrm{t}$ for the manure nitrogen spreading. Manure management entails storage systems and treatments for its use, plus costs for maintenance, all of which are in short supply in the Campania region.

It may be necessary to introduce integrated manure management policies. However, this framework is quite unlikely to be enacted in the near future, because it would entail high costs for the transport of manure, given the dilute nature of manure slurries. Hence, farms should be encouraged to adopt liquid-solid separation treatments to reduce costs by $30-40 \%$ (the solid fraction is more economically transported than the liquid one). A portion of the liquid fraction could be used in loco and the remaining (approximately 30\%) regionally.

A further change might be to relocate livestock farming, even if it does not seem desirable from an occupational and entrepreneurial point of view. Finally, it may be possible to introduce manure treatment technologies, but the energy costs and the equipment required may be prohibitive in the current livestock production system. It is the authors' opinion that the ratio between the cost of spreading manure and the benefits due to nitrogen content is critical to drive the planning process. The intervention of specific experts to manage and introduce economic-managerial structures for the entire milk production system would be highly desirable. Moreover, economic interventions to encourage manure utilisation for its nutrient content are likely to be necessary.

In conclusion, we maintain that management of livestock waste in the Campania region of southern Italy is not well controlled and carried out, in almost all cases, without the necessary facilities and infrastructures. It is very possible that other EU areas have manure management issues similar to the area studied in this paper. A more focused and complex multifunctional regional plan, oriented towards a more comprehensive environmental management system, would be highly appropriate.

\section{References}

Allocca V, Celico F, De Vita P, Fabbrocino S, Mattia C, Monacelli G, Musilli I, Piscopo V, Scalise A, Summa G, Tranfaglia G, 2003. Note illustrative della Carta Idrogeologica dell'Italia Meridionale. Istituto Poligrafico e Zecca dello Stato, Roma, Italy.

Arheimer B, Andersson L, Larsson M, Lindström G, Olsson J, 2004. Modelling diffuse nutrient flow in eutrophication control scenarios. Water Sci Technol 49, 37-45.

Badri BB, Apan AA, Raine SR, 2002. Geographic information system based manure application plan. J Environ Manage 64, 99-113.

Boccia L, Ripa MN, Iannotta F, Leone A, 2003. Nitrate pollution from agricultural and livestock sources in Volturno basin. Proceedings of the CIOSTA-CIGR Congress, Turin (22-24 September 2003) 2, 593-600.

Burton CH, Turner C, 2003. Manure management. Treatment strategies for sustainable agriculture. 2nd ed. Silsoe Research Institute, Wrest Park-Silsoe-Bedford, UK.

Fine DH, Ross R, Rounbehler DP, Silvergleid A, Song L, 1977. 
Formation in vivo of volatile $\mathrm{N}$-nitrosamines in man after ingestion of cooked bacon and spinach. Nature 265, 753-755.

Frost A, 1999. A summary of the agricultural issues raised at the Conference. Water Sci Technol 39, 361-364.

Garnier M, Loporto A, Marini R, Leone A, 1999. Integrated use of GLEAMS and GIS to prevent groundwater pollution caused by agricultural disposal of animal waste. Environ Manage 22, 747-756.

Goovearts P, 1997. Geostatistics for Natural Resources Evaluation. Oxford University Press, New York, Oxford, USA.

Haycock NE, Muscutt AD, 1995. Landscape management strategies for control of diffuse pollution. Landscape Urban Plan 31, 313-321.

Ingenito MR, D’Antonio A, Bianco M, 2003. Guida alla concimazione. www.sito.regione.campania.it/Agricoltura/pubblicazioni/guida_concimazione.htm (accessed on August 2009).

ISTAT, 2000. Quinto censimento generale dell'agricoltura. Tavole statistiche, Caserta (Tav. 2.29). http://www. census.istat.it (accessed on August 2009).

Kamarkar S, Lague C, Agnew J, Landry H, 2007. Integrated decision support system, DSS for manure management: a review and perspective. Comput Electron Agr 57, 190-201.

Kuipers A, Mandersloot F, 1999. Reducing nutrient losses on dairy farms in the Netherlands. Livest Prod Sci 61, 139144.

McColl C, Aggett G, 2007. Land-use forecasting and hydrologic model integration for improved land-use decision support. J Environ Manage 84, 494-512.

Miller RC, Guertin DP, Heilman P, 2004. Information technology in watershed management decision making. J Am Water Res Ass 40, 347-357.

Neeteson JJ, 2000. Nitrogen and phosphorus management on Dutch dairy farms: legislation and strategies employed to meet the regulations. Biol Fert Soils 30, 566-572.

Ondersteijn CJM, Beldman ACG, Daatselaar CHG, Giesen GWJ, Huirne RBM, 2003. Farm structure or farm management: effective ways to reduce nutrient surpluses on dairy farms and their financial impacts. Livest Prod Sci 84, 171-181.

Onorati G, Imperatrice ML, Di Meo T, D’Antonio A , 2003. State of implementation of nitrate directive. Proceedings of the Congress "Agricultural systems and nitrate pollution", Perugia (Italy), 11-12 December 2003.
Osei E, Gassman PW, Hauck LM, Jones R, Beran L, Dyke PT, Goss DW, Flowers JD, McFarland AMS, Saleh A, 2003. Environmental benefits and economic costs of manure incorporation on dairy waste application fields. J Environ Manage 68, 1-11.

Provolo G, 2000. Il trasporto dei liquami ed i relativi cantieri, i costi di distribuzione. DI.RE.ZO. Distribuzione dei REflui ZOotecnici, Regione Lombardia, Italy.

Ramos MC, Quinton JN, Tyrrel SF, 2006. Effects of cattle manure on erosion rates and runoff water pollution by faecal coliforms. J Environ Manage 78, 97-101.

Rekolainen S, Grönroos J, Bärlund I, Nikander A, Laine Y, 1999. Modelling the impacts of management practices on agricultural phosphorus losses to surface waters of Finland. Water Sci Technol 39, 265-272.

Sharpley AN, Chapra SC, Wedepohl R, Sims JT, Daniel TC, Reddy KR, 1994. Managing agriculture phosphorus for protection of surface waters: issues and options. J Environ Qual 23, 437-451.

Sims J, Goggin N, McDermott J, 1999. Nutrient management for water quality protection: integrating research into environmental policy. Water Sci Technol 39, 291-298.

Stålnacke P, Grimvall A, Libiseller C, Laznik M, Kokorite I, 2003. Trends in nutrient concentration in Latvian rivers and the response to the dramatic change in agriculture. J Hydrol 283, 184-205.

Ter Haar Romeny BM, 2003. Front-end vision and multiscale image analysis: multi-scale computer vision theory and application, written in mathematics. Springer, the Netherlands.

Tesoriero AJ, Liebscher H, Cox SE, 2000. Mechanism and rate of denitrification in an agricultural watershed: electron and mass balance along groundwater flow paths. Water Resour Res 36, 1545-1559.

Thayalakumaran T, Bristowa KL, Charlesworth PB, Fass T, 2008. Geochemical conditions in groundwater systems: implications for the attenuation of agricultural nitrate. Agr Water Manage 95, 103-115.

Viaud V, Merot P, Baudry J, 2004. Hydrochemical buffer assessment in agricultural landscapes: from local to catchment scale. Environ Manage 34, 559-573.

Westerman PW, Bicudo JR, 2005. Management considerations for organic waste use in agriculture. Bioresource Technol 96, 215-221. 